\title{
Embedded System Design and Implementation of an Intelligent Electronic Differential System for Electric Vehicles
}

\author{
Ali UYSAL \\ Technology Faculty, Department of Mechatronics \\ Engineering, Karabük University \\ Karabük, TURKEY
}

\author{
Emel SOYLU \\ Technology Faculty, Department of Mechatronics \\ Engineering, Karabük University \\ Karabük, TURKEY
}

\begin{abstract}
This paper presents an experimental study of the electronic differential system with four-wheel, dual-rear in wheel motor independently driven an electric vehicle. It is worth bearing in mind that the electronic differential is a new technology used in electric vehicle technology and provides better balancing in curved paths. In addition, it is more lightweight than the mechanical differential and can be controlled by a single controller. In this study, intelligently supervised electronic differential design and control is carried out for electric vehicles. Embedded system is used to provide motor control with a fuzzy logic controller. High accuracy is obtained from experimental study.
\end{abstract}

Keywords-Electronic differential; electric vehicle; embedded system; fuzzy logic controller; in-wheel motor

\section{INTRODUCTION}

In road transport systems, the differential plays an important role in preventing the vehicle from slipping in curved roads. In practice, mechanical differentials are used, but they are cumbersome due to increased weight. Also, electric vehicles are not particularly suitable for those who use separate drives for both rear wheels. The electronic differential system (EDS) constitutes the latest technological developments in the design of electric vehicles, provide better control and balancing of a vehicle in curved paths [1].

In automotive engineering, an EDS is a differential form that provides the torque needed for each driving wheel and allows for different wheel speeds, used in place of the mechanical differential in multiple drive systems. When cornering, the inner and outer wheels rotate at different speeds because the inner wheels define a smaller radius of rotation. The EDS controls the power of each wheel, using the steering wheel control signal and engine speed signals, thus providing all the wheels with the torque they need.

The EDS scheme has several advantages over the mechanical differential. These are simplicity that avoids additional mechanical components such as a gearbox or clutch, independent torque for each wheel provides additional capabilities (e.g. traction control, stability control), reprogrammable to add new features or adjusted to the driver's preferences, allows distributed regenerative braking, as with a mechanical differential, torque is not limited by the leastwheeled wheel, fast response time, accurate information on torque per wheel [2].

In this work, the intelligent supervised EDS for electric vehicles is designed and realized. There are studies in this issue in the literature. This technology has many applications and vehicle performance has been improved with successful applications. The movement of this earthmoving truck is provided by an electric drive system consisting of two independent electric motors. Providing a maximum power of $2700 \mathrm{~kW}$, these engines are controlled to adjust their speed when cornering, thereby increasing traction and reducing tire wear. Eliica is also equipped with an EDS. This eight-wheel electric vehicle has the ability to drive up to $370 \mathrm{~km} / \mathrm{h}$ with excellent torque control on each wheel. There are also microcontroller systems for smaller vehicles and general vehicle applications for traction.

In an EDS designed for an electric vehicle driven by two induction motors, five joint transducers were used in the control of two induction motors. The performance of the five joint transformers with two induction motor drives was compared [3]. The DSP TMS320LF2407 is used as the controller for twin-wheel induction motor-driven electronic differential systems. In the proposed front-wheel drive system, direct torque control, adaptive flux and fast observer-based algorithms are used [4]. Two electric motors with permanent magnets are used in an EDS operation to ensure that the electric vehicle is able to achieve better road holding in rough roads. At this point, the losses of the gear systems have been destroyed. As a result of their simulation, the control of electric vehicle engines in slippery and winding roads is provided with high accuracy thanks to the EDS [5].

In an EDS design that will provide good vehicle stability on a rough road, the traction system is provided by two permanent magnet synchronous motors (PMS) on the rear wheels. With the proposed control structure, the torque for each hub motor is controlled by fuzzy logic. Different simulations have been made: the straight road, the slope, the drive on the straight road, and the drive on the road. Simulation results show that a good vehicle stabilizes on a curved path [6]. The control of the electric differential of an electric vehicle using the direct torque control method has been carried out. Direct torque control of 
the electric vehicle is modeled in Matlab/Simulink environment [7].

In a study to provide an efficient and robust control scheme for the EDS for an electric vehicle, two brushless DC motors (BLDC) are used to drive the two rear wheels of an electric vehicle. Maximum torque is provided and controlled by Electronic Differential Control (EDC). The effectiveness and robustness of the proposed methods have also been confirmed and experimentally verified in the Matlab/Simulink environment [8]. A modeling and simulation of an EDS are performed using a new wavelet transform controller for two brushless DC motors to drive the right and left rear wheels. Numerical simulation test results of controllers are presented on a straight road, right turning and left turning to verify operation [1].

In a study in China, numerical simulations of four-wheel electric vehicles have been carefully studied on control performance. The results show that EDS feedback gain plays an important role in control performance, especially in terms of steering characteristics. In addition, analysis and discussion reveal the mechanics of the relationship between feedback gain and steering characteristics [9]. EDS control in a mini electric vehicle with two-wheel electric motor uses torque and twomile slip ratio balance as control variables of wheel torque, taking into account the effects of axle load transfer [10].

PID methods have been used with neural networks in the EDS speed setting of a vehicle consisting of four wheel motors. According to the steering kinematics, a three-degree-offreedom dynamic steering model has been provided and an EDS speed control system for the four-wheel motor has been proposed [11]. In a simulation study, a fuzzy logic controlled EDS for an electric vehicle with two wheels was designed. With fuzzy logic, the slip rate for each wheel is calculated in a complex and nonlinear system. Then the necessary power and torque distribution are made with the EDS. The efficiency and validity of the proposed control method are evaluated in Matlab/Simulink environment. The simulation results show that the new EDS control system can maintain the slip ratio in the optimum range, thus ensuring the vehicle has a smooth or curved lane stability [12]. Fuzzy logic controller provides good performance at closed-loop feedback control systems [13].

According to the fast development of electronic technology and requirements of electronic markets, electronic products aim to become smaller and faster [14]. In this study, fuzzy logic controlled EDS was realized with an embedded system. Using embedded systems has some advantages such as less coding, ease of use, practicality, flexibility, fast building time, time-savings, and reliability. With the aforementioned reasons, the study contributes to researchers, manufacturers, research and development laboratories that are related to this area [15]. The system was tested on a four-wheeled vehicle powered by two motors from the rear. The vehicle's physical measurements and steering position information are applied to the EDS. Speed control with fuzzy logic is performed according to the calculated left and right motor reference speed information. In this case, according to mechanical differential electrical vehicles, the mechanical differential losses are eliminated and the friction of the electric vehicle will be reduced and energy saving will be achieved.

In the second section of this study the detailed information and mathematical equations about EDC are given. The following section is about the design and control algorithm of the system. Brief description of fuzzy logic algorithm is used in this study and system's integrated scheme is located in that section. MATLAB model of the intelligent supervised electronic differential system is given and their explanations are made. The electric vehicle used in electronic differential tests is illustrated and the specifications of the vehicle are given. The graphics of experimental studies are shown. Finally in conclusions section the importance of EDS is emphasized and accuracy of the developed system is displayed. The advantage of this study and future scope of the paper are discussed.

\section{ELECTRONIC DIFFERENTIAL SYSTEM}

The EDS is a system that controls the speeds of the drive motors so that the difference between the speeds of the inner wheels and the speeds of the outer wheels can be obtained when two independent motorized electric vehicles are turning the vehicle's bends. Here the EDS fulfill the role of the mechanical differential in single-drive multi-drive vehicles. The structure of the vehicle is given in Fig. 1. There are two independent engines that drive the wheels 3 and 4 of this vehicle. Where $\mathrm{L}$ is the distance between the front and rear wheels of the vehicle, $d$ is the distance between the front or rear wheels, $\theta$ is the steering angle of rotation, $\omega_{\mathrm{V}}$ is the ang.

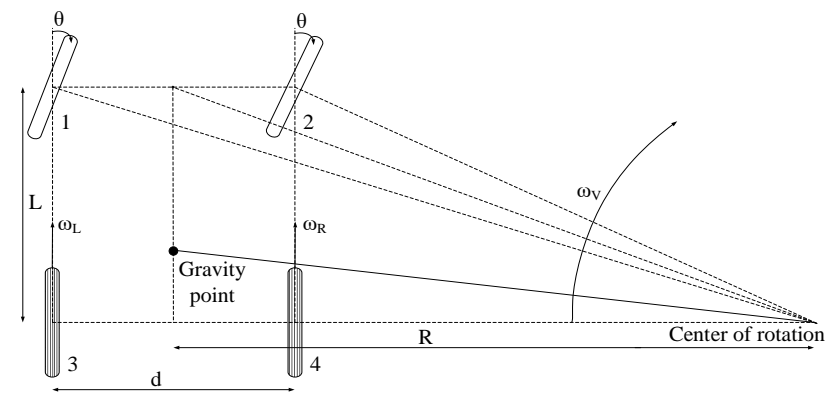

Fig. 1. The structure of the vehicle.

The speed of the left and right wheels connected to the vehicle's drive motors is a function of the angular velocity of the vehicle. Angular velocities of left and right wheels are calculated using $\omega \mathrm{L}$ and $\omega \mathrm{R}$ using (1) and (2) [8].

$$
\begin{aligned}
& \mathrm{V}_{\mathrm{L}}=\omega_{\mathrm{V}}\left(\mathrm{R}+\frac{\mathrm{d}}{2}\right) \\
& \mathrm{VR}=\omega_{\mathrm{V}}\left(\mathrm{R}-\frac{\mathrm{d}}{2}\right)
\end{aligned}
$$

$\mathrm{R}$, the vehicle's radius of rotation, is a function of the vehicle steering position. $R$ is calculated using (3).

$$
\mathrm{R}=\frac{\mathrm{L}}{\tan \theta}
$$


The angular velocities of the right and left drive motors, which depend on the steering position of the vehicle, are calculated using (4) and (5).

$$
\begin{aligned}
& \omega_{\mathrm{L}}=\omega_{\mathrm{V}} \frac{\mathrm{L}+\frac{\mathrm{d}}{2} \tan \theta}{\mathrm{L}} \\
& \omega_{\mathrm{R}}=\omega_{\mathrm{V}} \frac{\mathrm{L}+\frac{\mathrm{d}}{2} \tan \theta}{\mathrm{L}}
\end{aligned}
$$

The angular speed of the vehicle and the speed difference between the right and left wheels depending on the steering position is calculated by (6). The direction of rotation of the vehicle according to the steering position is determined by (7). The angular velocities of the left and right wheels are calculated by (8) and (9) according to the vehicle speed and the speed difference between the wheels.

$$
\begin{array}{r}
\Delta \omega=\omega_{\mathrm{L}}-\omega_{\mathrm{R}}=\frac{\mathrm{d} \cdot \tan \theta}{\mathrm{L}} \omega_{\mathrm{v}} \\
\left\{\begin{array}{lcc}
\theta>0 \rightarrow & \text { Turn } & \text { right } \\
\theta=0 \rightarrow & \text { Go } & \text { straight } \\
\theta<0 \rightarrow & \text { Turn } & \text { left } \\
& \omega \mathrm{L}=\omega \mathrm{V}+\frac{\Delta \omega}{2} \\
& \omega \mathrm{L}=\omega \mathrm{V}-\frac{\Delta \omega}{2}
\end{array}\right.
\end{array}
$$

The block diagram of the EDS is given in Fig. 2.

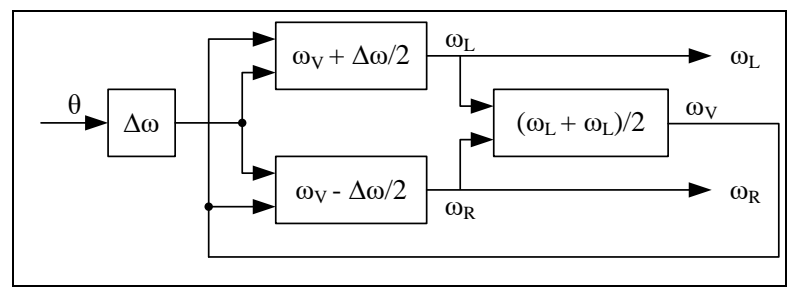

Fig. 2. Block diagram of the electronic differential.

\section{CONTROL OF ELECTRONIC DIFFERENTIAL SYSTEM VIA FUZZY LOGIC CONTROL}

The block diagram of the EDS designed in this study is given in Fig. 3. In this system, the STM32F4 Discovery development kit is used to control the EDS. The STM32F407VGT6 microcontroller on this card has $1 \mathrm{MB}$ Flash and $192 \mathrm{~KB}$ RAM. It has a 32-bit ARM Cortex-M4F core. Integrated ST-LINK/V2 JTAG debugger, running directly with USB or external power with $5 \mathrm{~V}, 3 \mathrm{~V}$ and $5 \mathrm{~V}$ output pins, 3-axis digital accelerometer, the outputs that enable the use of all 100 pins are other features of this development kit. The fuzzy logic controller is embedded to this microcontroller.

Matlab Fuzzy Logic Toolbox was used to create the fuzzy logic model of the experimental work and the control of the right and left motors was provided by the implemented fuzzy logic model. Speed control with fuzzy logic is performed according to the calculated left and right motor reference speed information. The error (e) and the change in the error (de) inputs $(\mathrm{du})$ are the motor speed. Seven sherds triangle type membership functions are used for input and output variables. The abbreviations NB, NM, NS, ZE, PS, PM and PB refer to linguistic variables "negative-big", "negative-medium", "negative-small", "zero", "positive small", "positive-medium" and "positive big", respectively. Fuzzy logic models for right and left motors were created after the input and output parameter adjustments were made and rule base was determined. Table 1 gives the rule base for this system. Fig. 4 shows the internal view of the right motor fuzzy logic controller block. Fig. 5 shows the MATLAB model of the intelligent supervised EDS embedded in the STM32F4. This model was created in Matlab/Simulink environment and embedded directly into the STM32F4 development card.

TABLE I. RULE BASE OF EDS

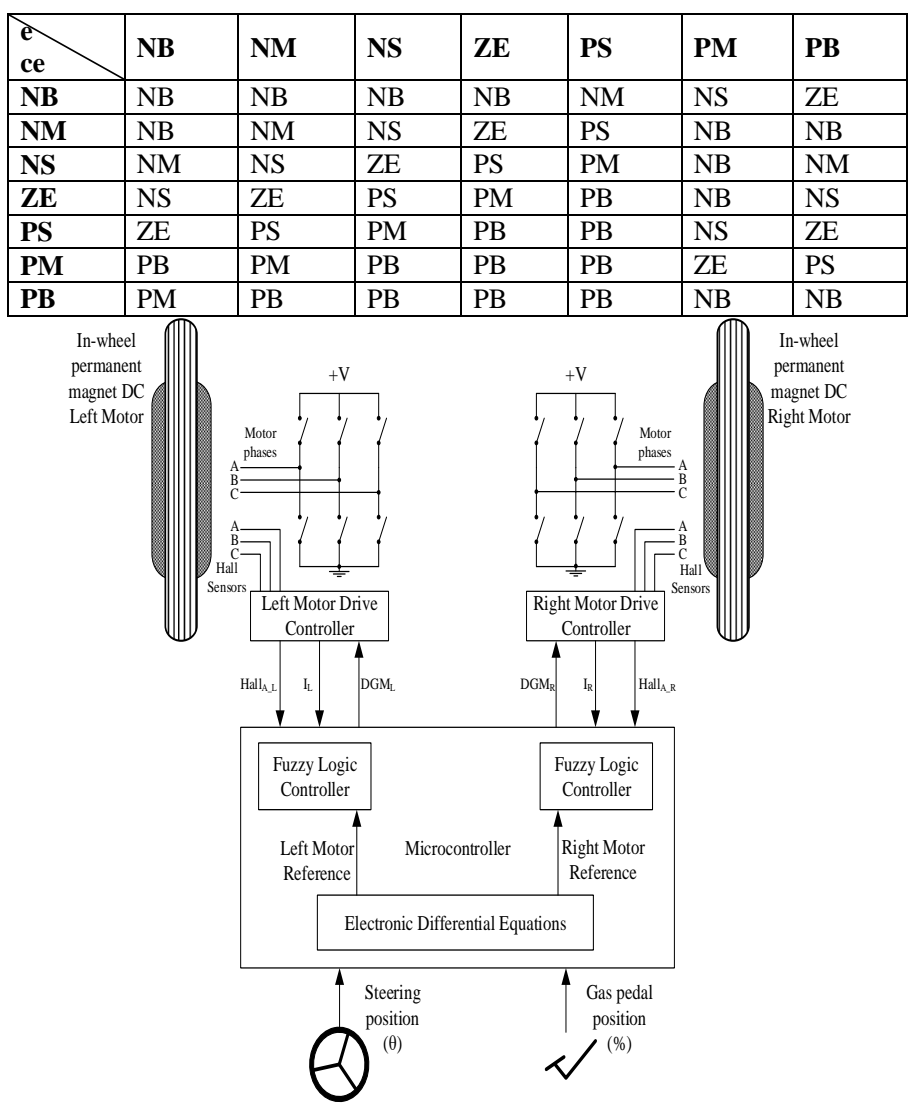

Fig. 3. The connection diagram of the electronic differential system.

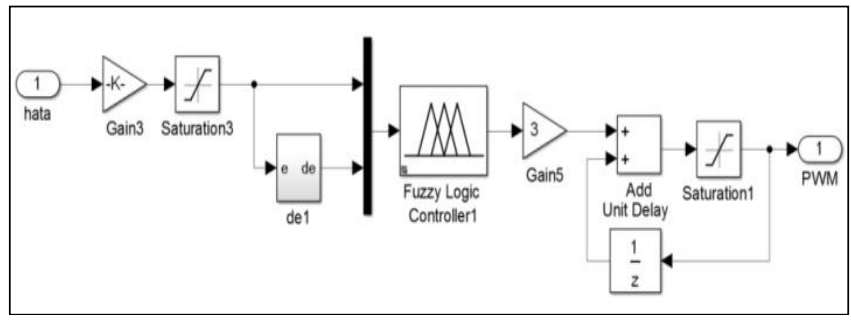

Fig. 4. The internal view of the right motor fuzzy logic controller block. 


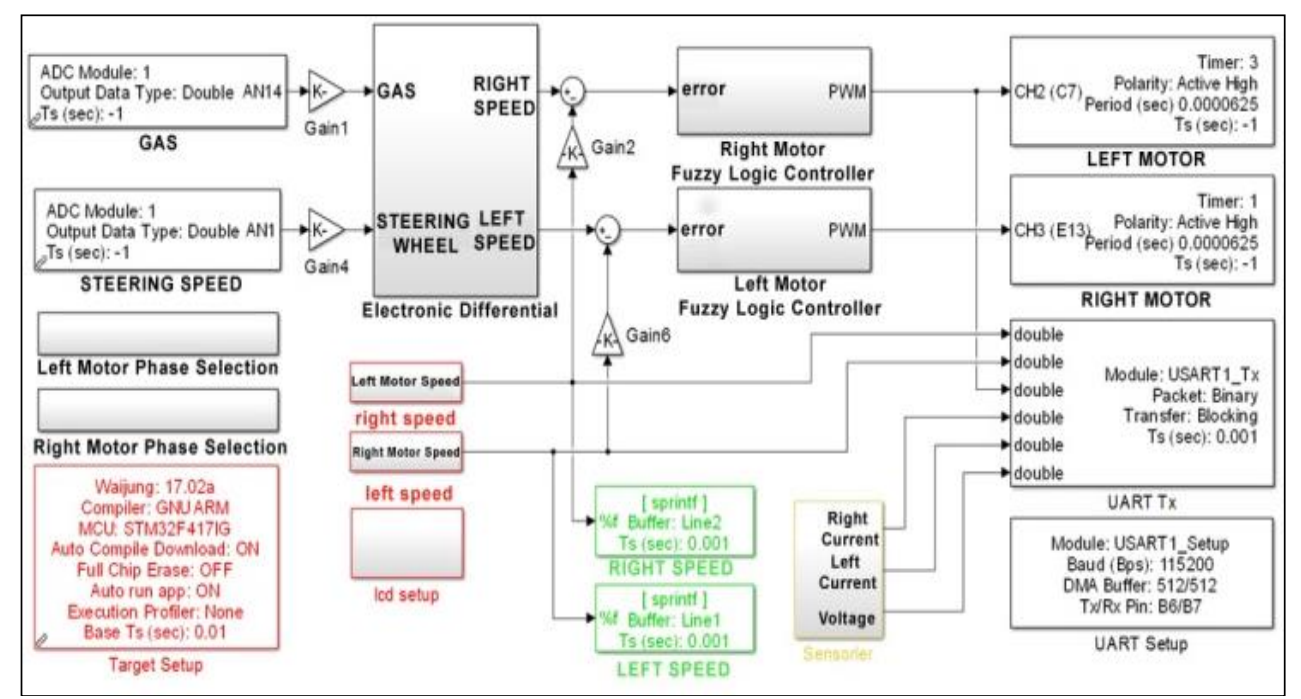

Fig. 5. MATLAB model of the intelligent supervised electronic differential system.

The electric car used in EDS experiments is given in Fig. 6. The card developed for the EDS application is zoomed. Left and right motor drivers are used to drive left and right HUB motors respectively. The control algorithm is embedded to the microcontroller of the system.

According to the simulation results, it has seen that the EDS calculates the reference speed information for the drive wheels according to the speed reference and steering positions. Fig. 8 gives the output signals of the fuzzy logic supervised EDS according to the $10^{\circ}$ steering position given in Fig. 7 and $100 \mathrm{rpm}$ reference speed value. The output signals of the fuzzy logic supervised EDS are given in Fig. 9 according to the $15^{\circ}$ steering position given in Fig. 7 and $100 \mathrm{rpm}$ reference speed value. Left and right DC motor speed curves are given in Fig. 10 , while steering position is $10^{\circ}$ and reference speed, is $200 \mathrm{rpm}$. Left and right DC motor speed curves are given in Fig. 11, while steering position is $15^{\circ}$ and reference speed, is $200 \mathrm{rpm}$.

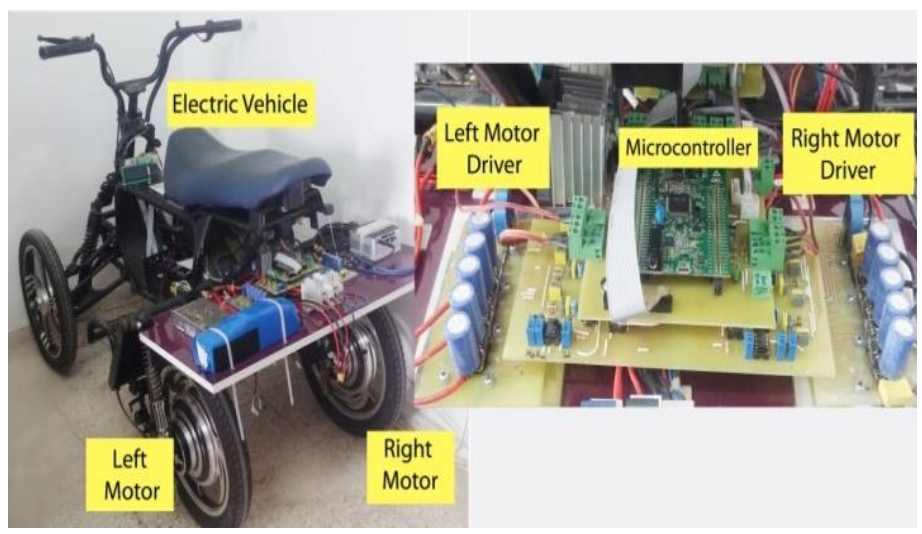

Fig. 6. The electric vehicle used in electronic differential tests.

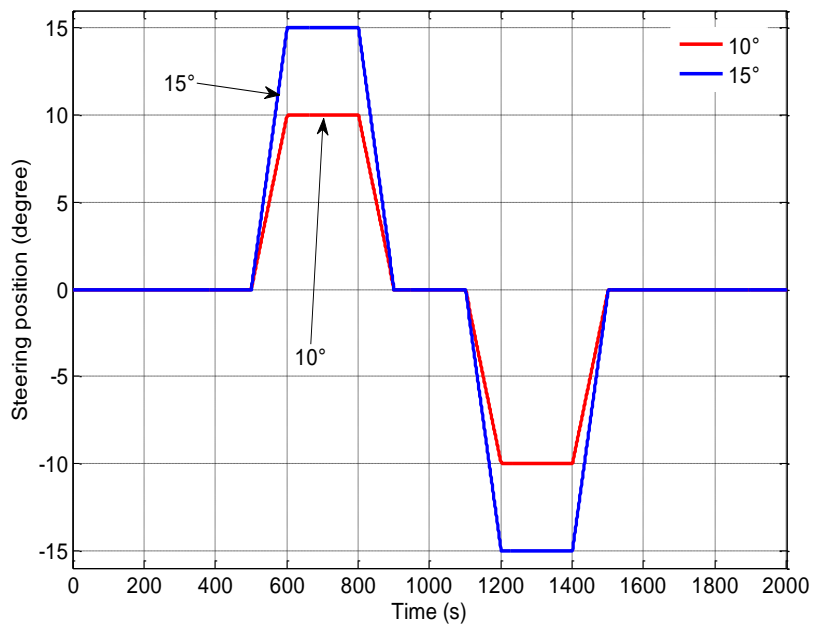

Fig. 7. Steering position $10^{\circ}$ and $15^{\circ}$.

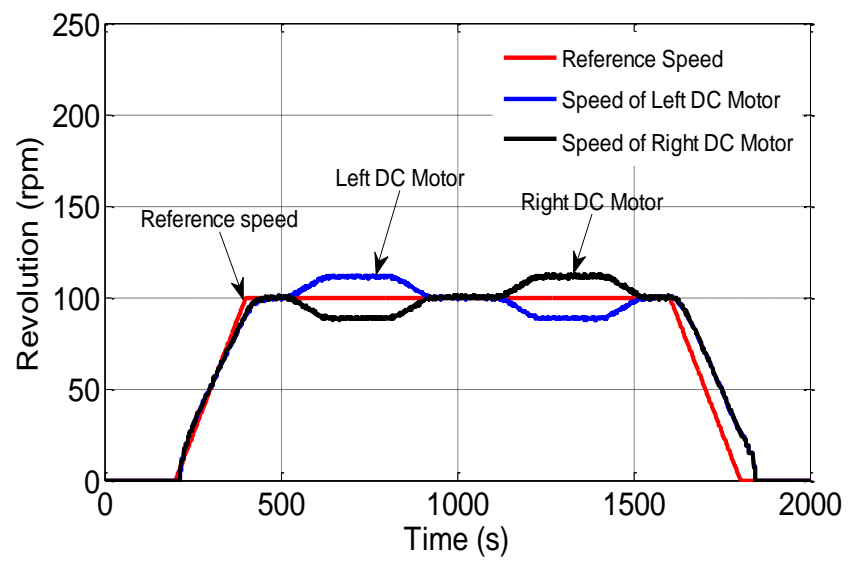

Fig. 8. Left and right motor speeds, while steering position is $10^{\circ}$ and reference speed, is $100 \mathrm{rpm}$. 


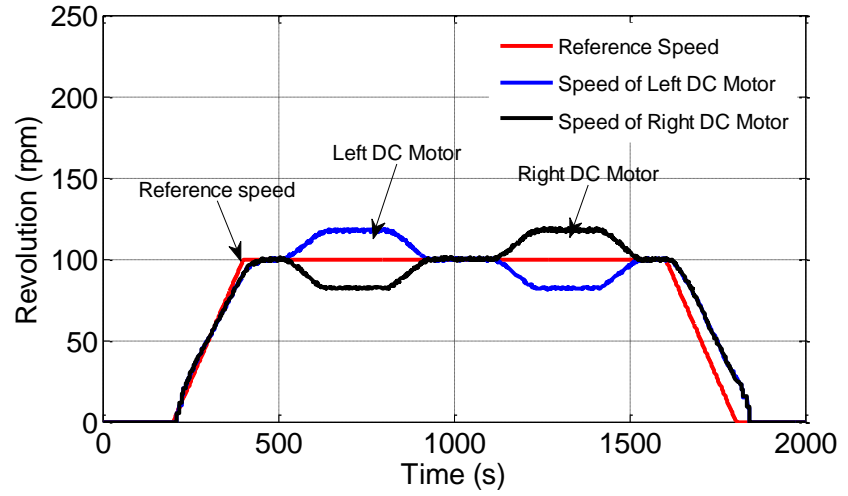

Fig. 9. Left and right motor speeds, while steering position is $15^{\circ}$ and reference speed, is $100 \mathrm{rpm}$.

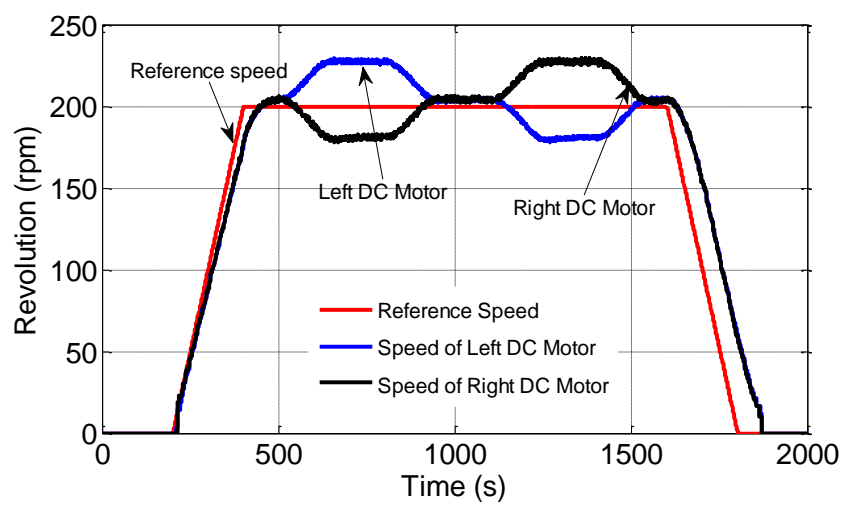

Fig. 10. Left and right motor speeds, while steering position is $10^{\circ}$ and reference speed, is $200 \mathrm{rpm}$.

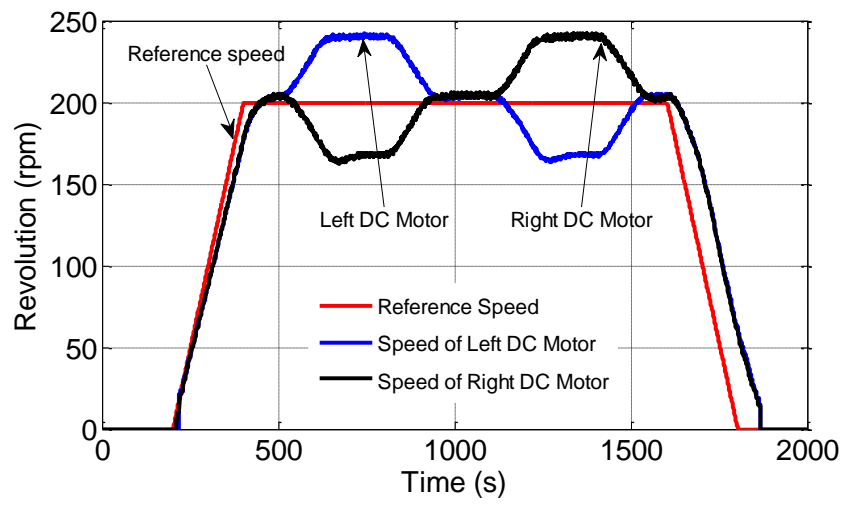

Fig. 11. Left and right motor speeds, while steering position is $15^{\circ}$ and reference speed, is $200 \mathrm{rpm}$.

Relative error between reference speed and average speed of two motors is calculated for each experiment at constant speed values. Average success rate of the system is obtained. The accuracy of the EDS is given in Table 2.

TABLE II. ACCURACY OF ELECTRONIC DIFFERENTIAL SYSTEM

\begin{tabular}{|l|l|l|l|}
\hline No & Steering Angle & Reference speed & Accuracy \\
\hline $\mathbf{1}$ & $10^{\circ}$ & 100 & $99.58 \%$ \\
\hline $\mathbf{2}$ & $15^{\circ}$ & 100 & $99.56 \%$ \\
\hline $\mathbf{3}$ & $10^{\circ}$ & 200 & $97.92 \%$ \\
\hline $\mathbf{4}$ & $15^{\circ}$ & 200 & $97.91 \%$ \\
\hline \multicolumn{2}{|l}{ Average success rate } & $\mathbf{9 8 . 7 4 \%}$ \\
\hline
\end{tabular}

\section{CONCLUSIONS}

In conclusion this study suggests an EDS instead of a mechanical differential system used in conventional electric vehicles. It occupies less space in the vehicle and saves the vehicle from a large metal mass. It can only be used on electric vehicles and is an alternative to internal combustion engines because there are many types of electric vehicle engines. Electric vehicle engines can be better controlled than internal combustion engines. The absence of the need for a power transmission system is also an advantage. In this study, intelligent supervised EDS design and control for electric vehicles were carried out. The fuzzy logic controller for motor control is embedded to STM32F4 Discovery development kit for four wheels, dual rearin-wheel motor independently driven an electric vehicle. In real-time experiments at 10 degrees and 15 degrees steering positions at $100 \mathrm{rpm}$ and $200 \mathrm{rpm}$ reference speeds the system performed with average $98.74 \%$ accuracy. The advantage of this study is that it is low cost. We are planning to make real time experiments using other type of control algorithms and make a comparison study in future work. This study is suitable on regenerative braking and cruise control applications.

\section{ACKNOWLEDGMENT}

Karabük University supported this study within the scope of Scientific Research Projects [KBÜ-BAP-14/2-DS-046].

\section{REFERENCES}

[1] F. J. L. Daya, P. Sanjeevikumar, F. Blaabjerg, P. W. Wheeler, J. O. Ojo, and A. H. Ertas, "Analysis of Wavelet Controller for Robustness in Electronic Differential of Electric Vehicles: An Investigation and Numerical Developments," Electr. Power Components Syst., vol. 44, no. 7, pp. 763-773, 2016.

[2] Y. Hori, "Future vehicle driven by electricity and control - Research on four-wheel-motored 'UOT Electric March II," IEEE Trans. Ind. Electron., vol. 51, no. 5, pp. 954-962, 2004.

[3] Z. Ibrahim, N. M. Yaakop, M. Sulaiman, J. M. Lazi, A. S. A. Hasim, and F. A. Patakor, "Electric differential with SVPWM direct torque control using five-leg inverter for electric vehicles," J. Theor. Appl. Inf. Technol., vol. 46, no. 2, pp. 599-609, 2012.

[4] B. Tabbache, A. Kheloui, and M. E. H. Benbouzid, "An adaptive electric differential for electric vehicles motion stabilization," IEEE Trans. Veh. Technol., vol. 60, no. 1, pp. 104-110, 2011.

[5] K. Hartani, Y. Miloud, and A. Miloudi, "Electric Vehicle stability with rear Electronic differential Traction," Int. Symp. Enviroment Friendly Energies Electrcal Appllcations, no. November, pp. 1-5, 2010.

[6] K. Hartani, M. Bourahla, Y. Miloud, and M. Sekour, "Electronic differential with direct torque fuzzy control for vehicle propulsion system,” Turkish J. Electr. Eng. Comput. Sci., vol. 17, no. 1, pp. 21-38, 2009.

[7] B. Gasbaoui, A. Chaker, A. Laoufi, B. Allaoua, and A. Nasri, "The efficiency of direct torque control for electric vehicle behavior improvement," Serbian J. Electr. Eng., vol. 8, no. 2, pp. 127-146, 2011.

[8] Ravi and S. Palani, "Robust electronic differential controller for an electric vehicle,” Am. J. Appl. Sci., vol. 10, no. 11, pp. 1356-1362, 2013.

[9] D. Yin, D. Shan, and J.-S. Hu, "A Study on the Control Performance of Electronic Differential System for Four-Wheel Drive Electric Vehicles," Appl. Sci., vol. 7, no. 1, 2017.

[10] S. Y. Hou, Z. Y. Li, T. Wang, L. L. Pang, and Z. Y. Feng, "Study on electronic differential control for a mini electric vehicle with dual inwheel-motor rear drive," in Applied Mechanics and Materials, 2014, vol. 525, pp. 346-350. 
[11] L. Zhai and S. Dong, "Electronic differential speed steering control for four in-wheel motors independent drive vehicle," Proc. World Congr. Intell. Control Autom., no. 1, pp. 780-783, 2011.

[12] Y. E. Zhao, J. W. Zhang, and X. Q. Guan, "Modeling and simulation of electronic differential system for an electric vehicle with two-motorwheel drive," IEEE Intell. Veh. Symp. Proc., pp. 1209-1214, 2009.

[13] W.-B. Xie, Y.-L. Wang, J. Zhang, and L. Huang, "Membership Function Dependent Observer-Based Controller Design for AT-S Fuzzy System," Asian J. Control, 2017.
[14] C.-M. W. C.-M. H. Kai-Chao Yang Yu-Tsang Chang, "Universal Learning System for Embedded System Education and Promotion," Int. J. Adv. Comput. Sci. Appl., vol. 4, no. 2, pp. 14-22, 2013.

[15] E. Soylu, T. Soylu, and R. Bayir, "Design and Implementation of SOC Prediction for a Li-Ion Battery Pack in an Electric Car with an Embedded System," Entropy, vol. 19, no. 4, 2017. 